\title{
Axial symptoms predict mortality in patients with Parkinson disease and subthalamic stimulation
}

Brian Lau, PhD, Niklaus Meier, MD, Giulia Serra, MD, Virginie Czernecki, PhD, Michael Schuepbach, MD, Soledad Navarro, MD, Philippe Cornu, MD, David Grabli, MD, PhD, Yves Agid, MD, PhD,

Marie Vidailhet, MD, PhD, Carine Karachi, MD, PhD, and Marie-Laure Welter, MD, PhD

Neurology ${ }^{\circledR}$ 2019;92:e2559-e2570. doi:10.1212/WNL.0000000000007562

\author{
Correspondence \\ Dr. Welter \\ marielaure.welter@ \\ icm-institute.org
}

\begin{abstract}
Objective

To characterize how disease progression is associated with mortality in a large cohort of patients with Parkinson disease (PD) with long-term follow-up after subthalamic nucleus deep brain stimulation (STN-DBS).
\end{abstract}

\section{Methods}

Motor and cognitive disabilities were assessed before and 1,2, 5, and 10 years after STN-DBS in 143 consecutive patients with PD. We measured motor symptoms "off" and "on" levodopa and STN-DBS and recorded causes of death. We used linear mixed models to characterize symptom progression, including interactions between treatment conditions and time to determine how treatments changed efficacy. We used joint models to link symptom progression to mortality.

\section{Results}

Median observation time was 12 years after surgery, during which akinesia, rigidity, and axial symptoms worsened, with mean increases of 8.8 (SD 6.5), 1.8 (3.1), and 5.4 (4.1) points from year 1-10 after surgery ("on" dopamine/“on" STN-DBS), respectively. Responses to dopaminergic medication and STN-DBS were attenuated with time, but remained effective for all except axial symptoms, for which both treatments and their combination were predicted to be ineffective 20 years after surgery. Cognitive status significantly declined. Forty-one patients died, with a median time to death of 9 years after surgery. The current level of axial disability was the only symptom that significantly predicted death (hazard ratio 4.30 [SE 1.50] per unit of square-root transformed axial score).

\section{Conclusions}

We quantified long-term symptom progression and attenuation of dopaminergic medication and STN-DBS treatment efficacy in patients with PD and linked symptom progression to mortality. Axial disability significantly predicts individual risk of death after surgery, which may be useful for planning therapeutic strategies in PD. 


\section{Glossary}

AUC $=$ area under the receiver operating characteristic curve; $H R=$ hazard ratio; IQR $=$ interquartile range; $L E D D=$ levodopa equivalent daily dose; MDRS = Mattis Dementia Rating Scale; PD = Parkinson disease; STN-DBS = deep brain stimulation of the subthalamic nucleus; UPDRS = Unified Parkinson's Disease Rating Scale; YO = young-onset.

In the last 20 years, deep brain stimulation of the subthalamic nucleus (STN-DBS) has been shown to be effective for reducing akinesia, rigidity, and tremor as well as gait and balance disorders in short (1-year) and medium duration (5-year) follow-up studies. ${ }^{1}$ Small cohort studies, with 12-34 patients, reported the effects of STN-DBS on Parkinson disease (PD) more than 7 years after surgery. These studies show sustained improvement of rigidity and tremor, but a progressive worsening of akinesia and decreasing efficacy for treating gait and balance disorders. ${ }^{2-4}$ The prevalence of dementia also increases, with a rate of 6\%-43\% 7-10 years after STN-DBS. ${ }^{2-4}$ In patients with PD with STN-DBS followed more than 7 years after surgery, death occurred in $30 \%$ of patients, with a mean delay of 23 years after disease onset and 5.5 years after surgery. ${ }^{2-5}$ In contrast, mortality occurs $7-15$ years after disease onset in nonoperated patients with $\mathrm{PD},{ }^{6}$ with 2 retrospective studies suggesting that patients with PD with STN-DBS may survive longer. ${ }^{7,8}$ It is therefore possible that relationships between long-term disease progression and death in STN-DBS patients differs from those in nonoperated patients.

The number of patients with PD with STN-DBS included in long-term studies is low and evidence is insufficient to predict the long-term outcome and mortality. ${ }^{9}$ Here, we aimed to model PD symptom progression and to determine how progression was associated with mortality in a large cohort of 143 STN-DBS patients with PD followed in our center for more than 10 years after surgery. We developed a statistical model for the long-term progression of different motor and cognitive outcomes, using the progression of these outcomes to predict the likelihood of death at the individual patient level.

\section{Methods}

\section{Patients}

In this longitudinal cohort study, we enrolled consecutive patients with PD operated for STN-DBS, including tremor dominant forms, at the Pitié-Salpêtrière Hospital between February 1996 and December 2003. We included patients for surgery using the following criteria ${ }^{10}$ : (1) age younger than 70 years; (2) a severe form of the disease (Hoehn \& Yahr stage $\geq 2.5$ ); (3) $>40 \%$ decrease in motor symptoms with levodopa treatment; and (4) presence of disabling levodopa-induced motor complications despite optimal medical treatment. Exclusion criteria included dementia (Mini-Mental State $<24$ or Mattis Dementia Rating Scale [MDRS] <130), ongoing psychiatric disturbances (e.g., major depressive episode, delirium), surgical contraindications (e.g., contraindication to anesthesia, coagulopathies, actual malignancy, uncontrolled hypertension), and relevant brain lesions (e.g., severe atrophy or major vascular brain lesions) detected on MRI. We performed clinical assessments according to our standard procedure for patients with PD with STN-DBS. ${ }^{11}$ In accordance with local clinical care during the enrollment period, patients were examined 1-3 months before surgery (preoperative assessment) and 1, 2, 5, and 10 years after surgery. The database was locked in July 2016, after a maximum observation period of 224 months.

\section{Standard protocol approvals, registrations, and patient consents}

This study received approval from the local ethics committee, and all patients gave written informed consent.

\section{Outcome measures}

To assess disease progression, we used the Unified Parkinson's Disease Rating Scale-III (UPDRS, motor disability). ${ }^{12}$ The UPDRS-III score ranges from 0 to 108, with 0 indicating absence of symptoms and 108 indicating maximal PD severity. Before surgery, UPDRS-III was performed in the 2 dopaminergic treatment conditions: "off" dopamine, after an interruption of at least 12 hours in antiparkinsonian medication, and "on" dopamine, after the administration of a single suprathreshold dose of levodopa (50 mg more than the usual effective dose taken in the morning before surgery). After surgery, the UPDRS-III was performed in 4 treatment conditions: (1) "off" dopamine/"on" STN-DBS, with the usual STN-DBS settings; (2) "off" dopamine/"off” STN-DBS, after stimulation had been switched off for at least 1.5 hours; (3) "on" dopamine/"off" STN-DBS, with the same levodopa dosage used for the preoperative assessment; and (4) "on" dopamine/"on" STN-DBS, after stimulation had been switched on with the usual STN-DBS settings. ${ }^{10,11}$ Evaluations were performed the same day and in the same order for all patients. We calculated 4 composite motor scores from UPDRS-III: (1) akinesia (sum of the face item 19; hands items 23, 24, 25; feet item 26; and global akinesia item 31, range $0-40)$; (2) rigidity (items 22 , range $0-20$ ); (3) tremor (items 20, 21, range 0-28); and (4) axial (speech item 18; arising from a chair item 27; posture item 28; gait item 29; and postural stability item 30 , range $0-20$ ).

We assessed cognitive status with the MDRS, ranging from 0 to 144 , with higher values indicating higher cognitive status, dementia being considered when the MDRS $<130 .{ }^{13} \mathrm{We}$ assessed the severity of hallucinations using item 4 of UPDRSI (range 0-4). ${ }^{12}$

Stimulation parameters, dopaminergic medication, and levodopa equivalent daily doses (LEDD) were recorded at every 
visit. We measured the severity of levodopa-related complications with UPDRS-IV (range 0-44).

All surviving patients were followed annually in our center during outpatient visits, except for patients lost to follow-up, and a neurologist (M.-L.W.) verified the cause of death when it occurred.

\section{Statistical analysis}

We used joint models for longitudinal and time-to-event data $^{14}$ to characterize symptom progression and to determine how progression was associated with survival. A separate joint model was fitted to the longitudinal and survival data for each symptom score, and each joint model consisted of 2 linked submodels. The first submodel is a linear mixed model capturing progression of a particular symptom, using year since surgery as the time variable. Scores were transformed using the square root to stabilize and normalize residuals. We included by-patient random intercepts and random slopes for time. The second submodel is a proportional hazard model that characterizes how the longitudinally measured symptom (estimated using the first submodel) predicts risk of death. We modeled the baseline risk function using a Weibull distribution.

The longitudinal submodel for symptoms measured under different treatment conditions (akinesia, rigidity, tremor, and axial symptoms) included a factor to determine how dopaminergic medication and STN-DBS affected motor disability ("off” dopamine/“off” STN-DBS, “on” dopamine/“off” STNDBS, “off” dopamine/“on" STN-DBS, "on” dopamine/“on” STN-DBS). We tested for changes in treatment effect using an interaction between the condition factor and the time variable. We adjusted for the following preoperative characteristics: sex, age at onset, disease duration, akinesia, rigidity, tremor, and axial symptoms measured without dopaminergic treatment ("off" dopamine) prior to surgery, and sensitivity to dopaminergic medication (fractional change in a symptom during the preoperative levodopa challenge and its interaction with treatment condition).

In the survival submodel, we estimated the risk of death associated with symptom severity by including the symptom severity estimated by the longitudinal submodel at each time as a predictor. We adjusted for the following preoperative characteristics potentially associated with mortality: sex, year of surgery, age at surgery, disease duration, preoperative measures of akinesia, rigidity, tremor and axial severity, cognitive status, and complications due to dopaminergic therapy. The survival submodel yielded hazard ratios (HRs) for the preoperative factors and an HR for the association between current symptom severity and mortality. For the motor outcomes measured under different treatment conditions, all 4 treatment conditions were used in the survival submodel. For each visit, the predicted score for all conditions was weighted by the same coefficient, which assumes that incremental outcome changes are treated identically for all treatment conditions.
We assessed model robustness several ways. We performed a sensitivity analysis and calculated E-values to determine the degree to which potential unmeasured confounding could explain away associations between symptom severity and death. ${ }^{15}$ The confounder associations are represented on risk ratio scale, and the HRs for current outcome severity from the joint models were converted to this scale using an approximation. ${ }^{16}$ The E-value represents one particular combination of confounder associations, and we visualized all potential combinations that explain away our associations of interest by varying the risk ratios for severity-confounder and death-confounder associations from 1 through 10 . We also examined the stability of mortality associations to different combinations of adjusting covariates in the survival submodel using a vibration of effects analysis. ${ }^{17}$ Full survival submodels each included parameters for 10 adjusting covariates (listed above) in addition to the parameter for measuring the association between the current level of an outcome and death. We fit a separate joint model for each possible combination of $k$ adjusting covariates, where $k$ varied from 1 to 10 , yielding 1,024 unique models for each outcome. For each unique model, we obtained an HR and $p$ value for the estimated association between the current level of an outcome and death. We examined the distribution of the joint values to visualize the instability of our results due to model specification.

We used a competing risks analysis to examine how different causes of death influenced our results. We stratified patients into those who died from causes related to PD severity and those who did not. We refit the joint models using a causespecific Cox regression for the survival submodel, yielding the associations between symptom severity and death for each patient strata.

We used averaged time-dependent area under the receiver operating characteristic curve (AUC) to measure the ability of our joint models to discriminate between patients who did and did not die. We used bootstrapping $(n=500)$ at the patient level to internally validate the models. We report AUCs corrected for optimism due to finite sample size. ${ }^{18}$

We used R (R Core Team, version 3.3.3) for all analyses. We tested significance of individual parameters using Wald tests using cluster-robust standard errors. These standard errors were obtained by resampling our dataset 1,000 times, with resampling performed at the patient level. ${ }^{19}$ Joint models were estimated for each bootstrap sample, and we calculated standard errors and $p$ values using cluster-robust variances estimated from the distributions of bootstrapped coefficients. We tested differences between parameters using likelihood ratio tests. All tests were 2 -sided, and we assessed test significance at the 0.05 level.

\section{Data availability statement}

All relevant data are within the article. Requests for anonymized data should be sent to B. Lau at the Brain and Spine Institute, Groupe Hospitalier Pitié-Salpêtrière, 75013 Paris, France. 


\section{Results}

\section{Cohort description}

Between February 1996 and December 2003, 143 patients with PD (37\% female, median age 57.0 years [interquartile range (IQR) 51-63]) underwent bilateral STN-DBS surgery 13 years (IQR 10-16) after PD onset. Median observation time from surgery was 144 months (IQR 107-164.5) with a median total disease duration of 24 years (IQR 19-28). Forty-one patients died during the follow-up period. Ninety patients completed the assessment at 10 years, 96 patients the assessment at 5 years, 108 the assessment at 2 years, and 142 the assessment at 1 year. Twelve patients missed the last assessment due to loss of follow-up (table e-1, doi.org/10.5061/dryad.6n70v4b).

\section{PD progression}

With time, akinesia severity increased without treatment $(p<$ 0.0001; figure 1; figure e-1, doi.org/10.5061/dryad.6n70v4b).
Applied alone, dopaminergic medication and STN-DBS both improved akinesia $(p<0.0001)$, with dopaminergic medication being more effective than STN-DBS $(p<0.0001)$. Combined treatment ("on" dopamine/"on" STN-DBS) was more effective than either treatment alone ( $p<0.0001$ for both comparisons). Treatment efficacy decreased over time, with STN-DBS alone ("off" dopamine/"on" STN-DBS $\times$ time) losing efficacy more slowly than dopaminergic medication alone ("on" dopamine/ "off" STN-DBS $\times$ time, $p=0.003$ ) or combined with STN-DBS (“on" dopamine/“on” STN-DBS $\times$ time, $p=0.002$ ).

Rigidity also worsened with time ( $p=0.0008$; figure 1 ; figure e-1, doi.org/10.5061/dryad.6n70v4b). Applied alone, dopaminergic medication and STN-DBS both improved rigidity $(p<0.0001)$ to a similar degree ( $p=0.23$ for comparison). Combined treatment ("on" dopamine/"on" STN-DBS) was more effective than either treatment alone ( $p<0.0001$ for both comparisons). Treatment efficacy decreased over time, with dopaminergic medication alone

Figure 1 Disease progression following deep brain stimulation of the subthalamic nucleus (STN-DBS) surgery

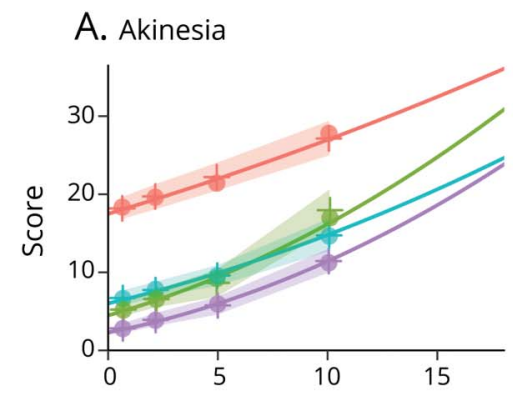

C. Tremor

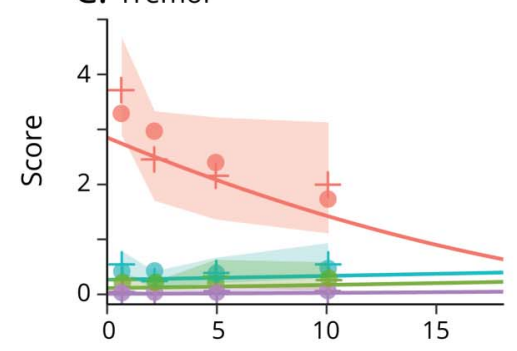

E. Hallucinations

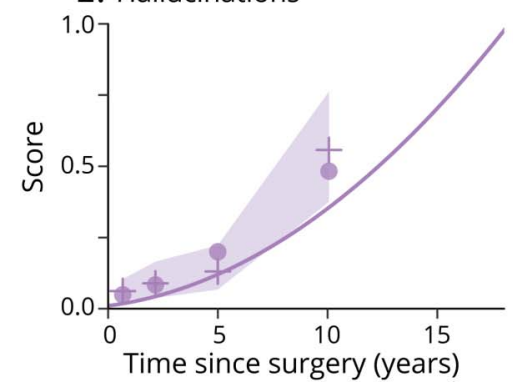

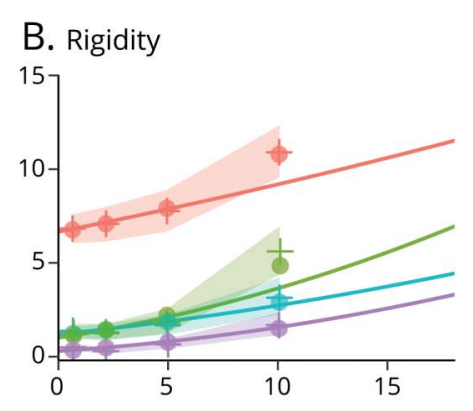

D. Axial

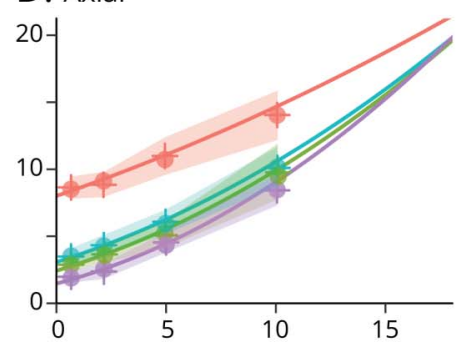

F. Cognitive status

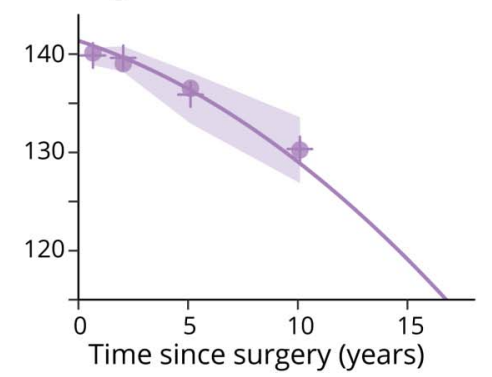

+ Mean $\pm 95 \% \mathrm{Cl}$

- Average model fit

- Model prediction for median male patient

"Off"dopamine/"Off"DBS

"On"dopamine/"Off"DBS

- "Off"dopamine/"On" DBS

"On"dopamine/"On" DBS

Each panel illustrates the progression of a particular symptom: (A) akinesia (range 0-40), (B) rigidity (range 0-20), (C) tremor (range 0-28), and (D) axial (range 0-20) scores were constructed using subsets of the Unified Parkinson's Disease Rating Scale (UPDRS) part III (see Methods), with higher scores indicating more severe symptoms. The scores are provided in the different conditions of treatment: without levodopa treatment and without stimulation ("off" dopamine/"off" STN-DBS, red); with levodopa treatment and without stimulation ("on" dopamine/"off" STN-DBS, green); without levodopa treatment and with stimulation ("off" dopamine/ "on" STN-DBS, blue); and with levodopa treatment and with stimulation ("on" dopamine/"on" STN-DBS, purple). (E) Hallucinations score was measured with the item 4 of UPDRS-I (range 0-4). (F) Cognitive status was assessed using the Mattis Dementia Rating Scale (range 0-144, with higher scores indicating better cognition). Each panel illustrates mean disability with corresponding $95 \%$ confidence intervals (Cls) (bootstrapped). The squares represent the mean patient-specific fit of the joint linear model, while the lines represent the model prediction for a male patient with the median preoperative characteristics of our cohort. 
("on" dopamine/"off" STN-DBS $\times$ time), losing efficacy more quickly than STN-DBS alone ("off" dopamine/"on" STN-DBS $\times$ time, $p=0.032$ ) but not when combined with STN-DBS ("on" dopamine/"on" STN-DBS $\times$ time, $p=0.21$ ).

Tremor severity significantly decreased with time $(p=0.0016$; figure 1; figure e-1, doi.org/10.5061/dryad.6n70v4b). Applied alone, dopaminergic medication and STN-DBS both improved tremor $(p<0.0001)$, with dopaminergic medication being more effective than STN-DBS $(p=0.011)$. Combined treatment ("on" dopamine/"on" STN-DBS) was more effective than either treatment alone ( $p<0.0003$ for both comparisons). Treatment efficacy decreased over time similarly for all treatment conditions ( $p>0.5$ for all comparisons).

Axial symptoms worsened rapidly over time $(p<0.0001$; figure 1; figure e-1, doi.org/10.5061/dryad.6n70v4b). Applied alone, dopaminergic medication and STN-DBS both

Figure 2 Factors associated with the progression of the axial symptoms

A

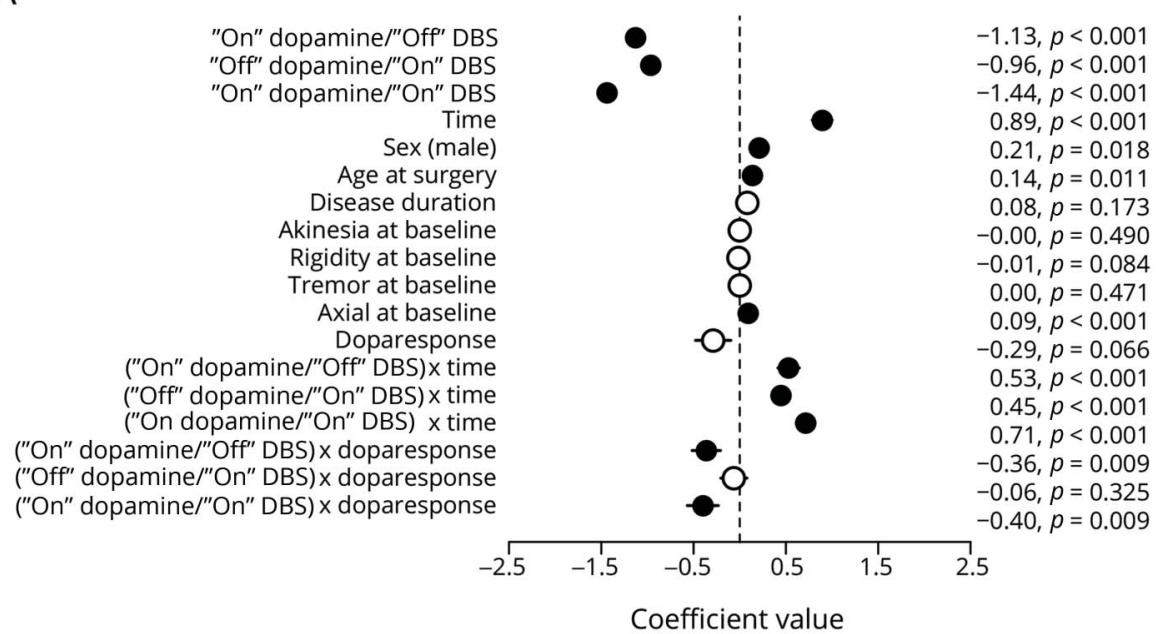

B
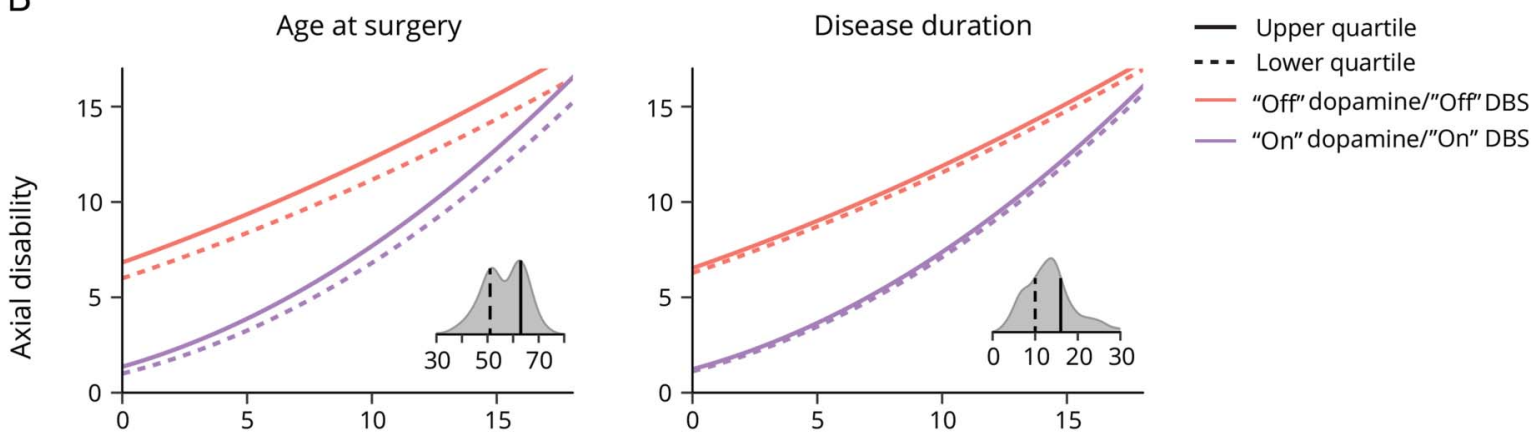

Dopa sensitivity at baseline

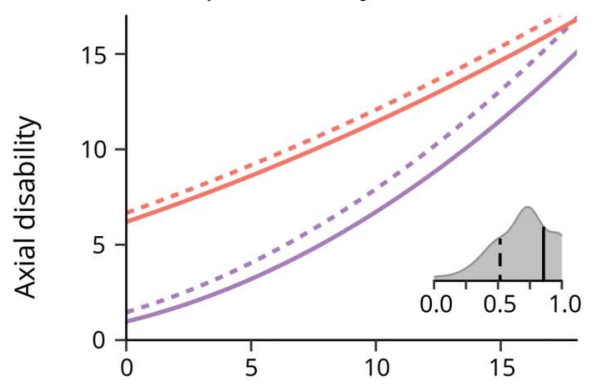

Time since surgery (years)

Axial disability at baseline

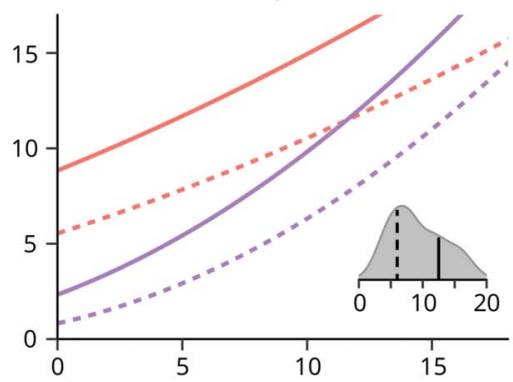

Time since surgery (years)

(A) Coefficients for longitudinal submodel of the joint model for axial disability. Values in units are square-root transformed axial score per covariate unit. Variables involving time (time, disease duration, treatment $\times$ time) are scaled per decade. Solid symbols represent significant effects $(p<0.05)$. Horizontal lines represent \pm 1 cluster-robust standard error on each parameter estimate. (B) Each panel illustrates the effect of a specific preoperative characteristic using the prediction of the longitudinal submodel of the joint model for axial symptoms. The solid lines represent the prediction for a male with the 75th percentile value for each specific characteristic, while the dashed lines represent the prediction for a male patient with the 25 th percentile value for each specific characteristic. In each panel, the other preoperative characteristics are held fixed at the median preoperative values of our cohort. Insets illustrate the distribution of the corresponding preoperative characteristic. DBS = deep brain stimulation. 
improved axial symptoms $(p<0.0001)$, with dopaminergic medication being more effective than STN-DBS $(p<0.0014)$. Combined treatment ("on” dopamine/“on" STN-DBS) was more effective than either treatment alone $(p<0.0001$ for both comparisons). Treatment efficacy decreased over time, with combined treatment ("on" dopamine/"on" STN-DBS $\times$ time) losing efficacy faster than STN-DBS ("off" dopamine/ "on" STN-DBS $\times$ time, $p=0.0095$ ) or dopaminergic medication alone ("on" dopamine/"off" STN-DBS $\times$ time, $p=$ $0.11)$. In contrast to the other motor symptoms, axial scores obtained under different treatments become indistinguishable by 18 years for a male patient with median preoperative characteristics, and converge most rapidly towards severity measured without treatment, with ineffectiveness of combined treatments for ameliorating axial symptoms predicted 20 years following surgery (figure 1).

In the case of akinesia, tremor, and axial symptoms, the severity of each symptom before surgery was significantly associated with the postsurgical severity of that specific symptom (akinesia $p=0.0019$, rigidity $p=0.08$, tremor $p<$ 0.0001 , axial $p<0.0001$; figure 2; figure e-1, doi.org/10.5061/ dryad.6n70v4b). The degree to which dopaminergic treatment ameliorated motor disability before surgery (dopa sensitivity) was significantly associated with postsurgical severity for all motor symptoms (akinesia $p<0.0001$, rigidity $p=0.025$, tremor $p=0.0035$, axial $p<0.0001$; figure 2 ).

Cognitive status declined with time $(p<0.0001$; figure 1 ; figure e-1, doi.org/10.5061/dryad.6n70v4b), and higher preoperative cognitive status reduced cognitive decline following surgery $(p<0.0001)$. The presence and severity of hallucinations significantly increased with time $(p<0.0001$; figure 1; figure e-1, doi.org/10.5061/dryad.6n70v4b).

Finally, LEDD was reduced by $72 \%, 64 \%, 60 \%$, and $62 \% 1,2$, 5 , and 10 years after surgery relative to before surgery (table e-2, doi.org/10.5061/dryad.6n70v4b).

\section{Mortality}

During the follow-up period, 41 (29\%) patients died (table 1). Twenty-five patients died due to PD progression with 12 patients unable to stand unassisted who were chronically bedridden and institutionalized, 7 patients who died from choking or aspiration pneumonia, and 3 patients who died from intestinal occlusion. Sixteen patients died due to other causes: cancer $(n=5)$, cardiovascular disease $(n=3)$, $\operatorname{mood}$ disorders $(\mathrm{n}=2 ; 1$ patient committed suicide and 1 patient had a car accident during a hypomanic episode potentially related to STN-DBS), or sudden death of unknown cause $(n=5)$. One patient died from severe orthostatic hypotension with autopsy revealing multiple system atrophy. None of the patients died from complications of the surgery. The median time to death was 107 months (IQR 56-138.3) after surgery.

Axial disability during the follow-up period was strongly associated with an increased risk of death (HR 4.30 [SE 1.50],
Table 1 Demographic and preoperative clinical characteristics of living and deceased patients with Parkinson disease with deep brain stimulation of the subthalamic nucleus

\begin{tabular}{llll}
\hline & $\begin{array}{l}\text { All } \\
\text { patients } \\
(\mathbf{n}=\mathbf{1 4 3})\end{array}$ & $\begin{array}{l}\text { Follow-up } \\
\text { obtained at } \\
\mathbf{1 0} \text { years }(\mathbf{n}=\mathbf{9 0})\end{array}$ & $\begin{array}{l}\text { Deceased } \\
(\mathbf{n}=\mathbf{4 1})\end{array}$ \\
\hline Sex, M/F & 0.63 & 0.60 & 0.59 \\
\hline Age at onset, $\mathbf{y}$ & $43.0(8.4)$ & $42.5(8.6)$ & $44.7(7.0)$ \\
\hline Age at surgery, $\mathbf{y}$ & $56.3(8.4)$ & $55.9(8.6)$ & $59.3(7.7)$ \\
\hline Disease duration, $\mathbf{y}$ & $13.4(5.5)$ & $13.4(5.7)$ & $14.6(5.4)$ \\
\hline
\end{tabular}

Motor disability

(UPDRS-III,/108)

\begin{tabular}{cccc}
\hline “Off" dopamine & $43.8(15.8)$ & $43.5(16.1)$ & $48.5(15.0)$ \\
\hline “On" dopamine & $10.5(8.9)$ & $10.5(9.8)$ & $13.8(9.4)$ \\
\hline
\end{tabular}

Akinesia (/40)

\begin{tabular}{llll}
\hline “Off" dopamine & $20.3(7.8)$ & $19.9(8.2)$ & $21.9(7.0)$ \\
\hline “On" dopamine & $5.0(4.7)$ & $5.1(5.2)$ & $6.1(5.5)$ \\
\hline
\end{tabular}

Rigidity (/20)

\begin{tabular}{llll}
\hline “Off" dopamine & $9.0(4.4)$ & $8.9(4.1)$ & $9.6(4.8)$ \\
\hline "On" dopamine & $1.9(2.6)$ & $1.9(2.8)$ & $2.4(2.6)$ \\
\hline
\end{tabular}

Tremor (/28)

\begin{tabular}{llll}
\hline “Off” dopamine & $5.3(5.3)$ & $5.8(5.7)$ & $5.2(4.9)$ \\
\hline “On” dopamine & $0.6(1.2)$ & $0.6(1.3)$ & $0.7(1.3)$ \\
\hline Axial symptoms (/20) & & & \\
\hline “Off” dopamine & $9.3(4.3)$ & $8.9(4.3)$ & $12.2(3.7)$ \\
\hline “On" dopamine & $3.1(2.7)$ & $2.9(2.8)$ & $4.7(3.0)$ \\
\hline $\begin{array}{l}\text { Cognitive status } \\
\text { (MDRS/144) }\end{array}$ & $138.1(6.3)$ & $138.4(6.6)$ & $136.5(9.1)$ \\
\hline $\begin{array}{l}\text { Hallucinations } \\
\text { (UPDRS I/16) }\end{array}$ & $0.3(0.6)$ & $0.3(0.6)$ & $0.3(0.6)$ \\
\hline $\begin{array}{l}\text { Levodopa-related } \\
\text { complications } \\
\text { (UPDRS IV/44) }\end{array}$ & $10.7(3.3)$ & $10.6(3.3)$ & $11.6(2.8)$ \\
\hline $\begin{array}{l}\text { Levodopa equivalent } \\
\text { daily dosage, mg/d }\end{array}$ & $1,327(603)$ & $1,281(504)$ & $1,623(828)$ \\
\hline
\end{tabular}

Abbreviations: MDRS = Mattis Dementia Rating Scale; UPDRS = Unified Parkinson's Disease Rating Scale.

Data are mean (SD). Higher scores for UPDRS subscores indicate higher severity of symptoms; lower score for MDRS indicates lower cognitive status.

$p=0.012$, figure 3 ). The joint model incorporating the current level of axial symptom severity best predicted which patients would die ( $83 \%$ accuracy), followed by the models incorporating akinesia (75\%), cognitive status (74\%), rigidity (72\%), tremor (70\%), and hallucinations (68\%). Finally, age at surgery was significantly associated with increased mortality for all outcomes except axial disability (akinesia $p=0.034$, rigidity 


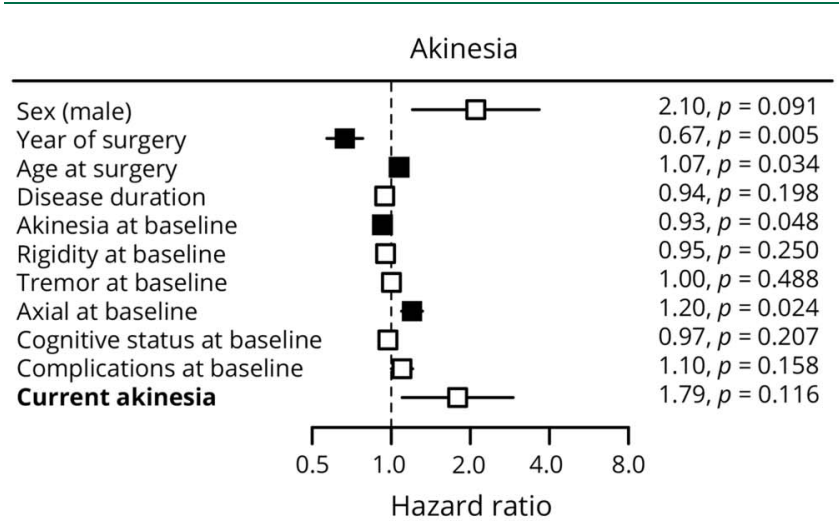

Tremor

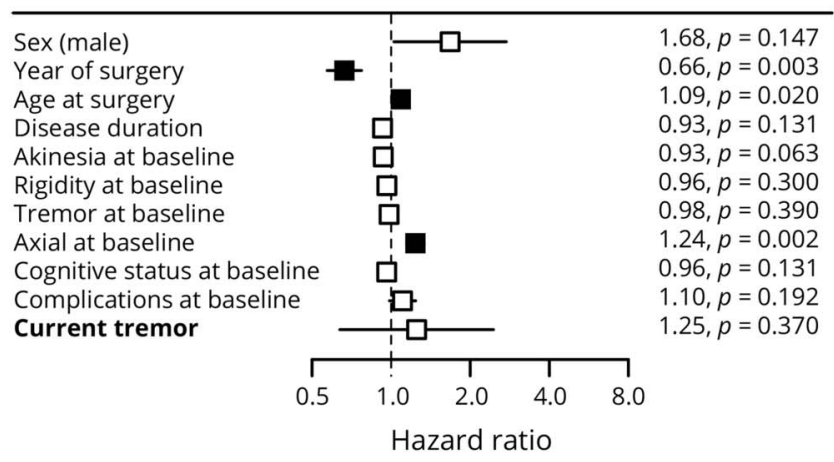

Hallucinations

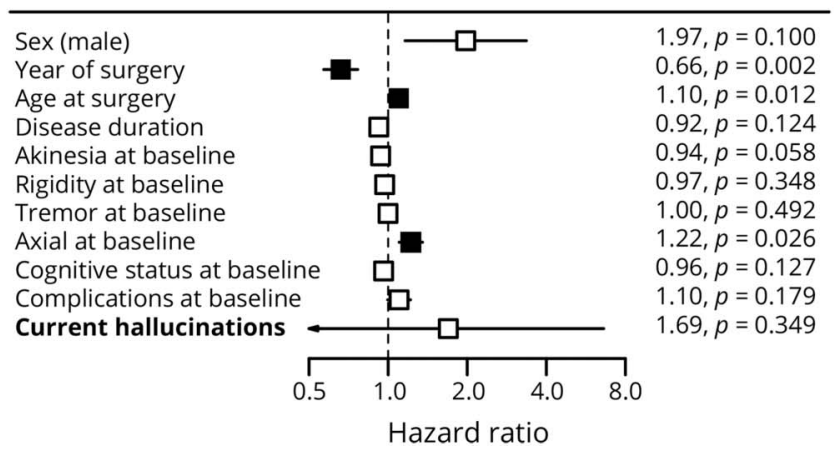

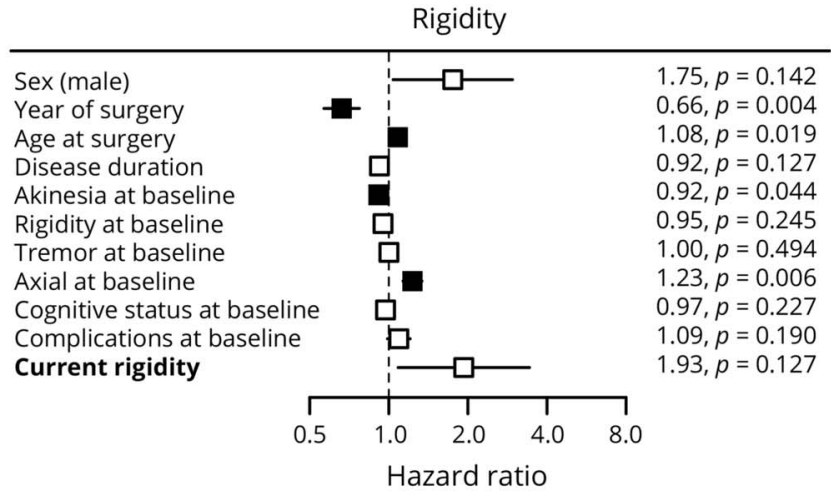

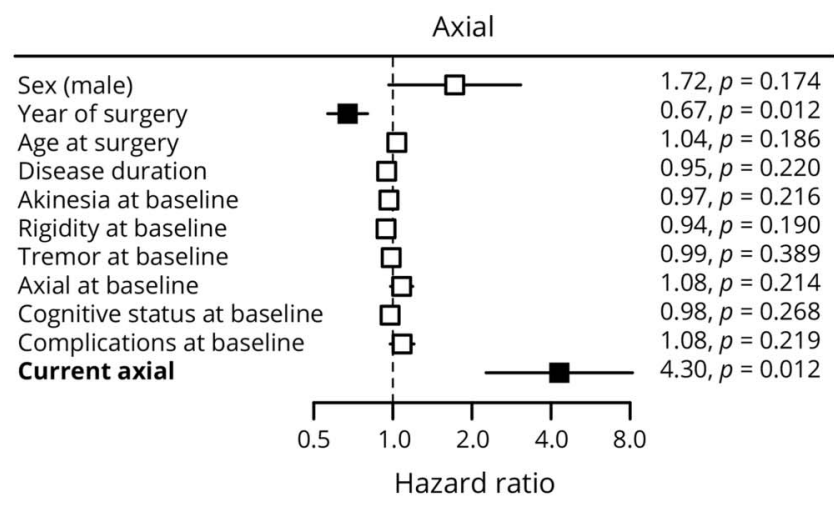

Cognitive status

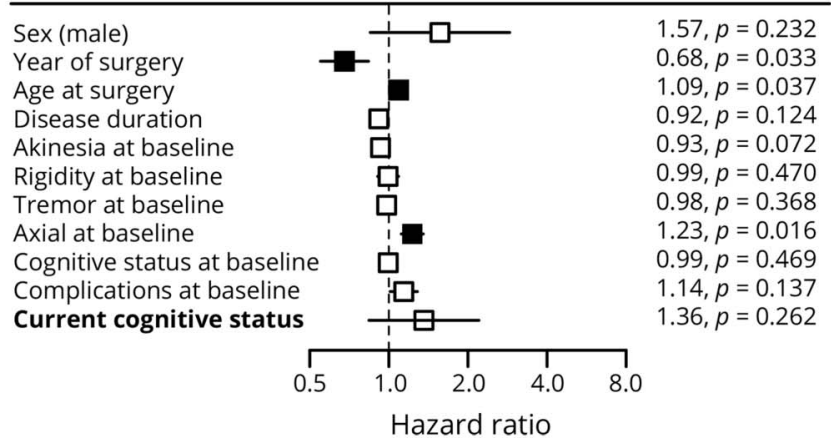

Each panel illustrates the hazard ratios (HRs) from the survival component of the joint linear mixed model. The last parameter (current outcome) in each panel corresponds to the HR summarizing the association between the current value of each symptom on mortality. Solid symbols represent significant effects $(p<$ 0.05). Horizontal lines represent \pm 1 cluster-robust standard error on each parameter estimate. Cognitive status was modeled as the observed score subtracted from the maximum score (144), such that positive HRs represent increased risk of death like the other outcomes.

$p=0.019$, tremor $p=0.02$, axial $p=0.186$, hallucinations $p=$ 0.012 , cognitive status $p=0.037$ ).

The association between axial disability and mortality was unlikely to be explained away by potential unmeasured confounders (figure 4), robust to the inclusion of different combinations of adjusting covariates (figure e-2, doi.org/10. $5061 /$ dryad.6n70v4b), and significant and of similar magnitude for each of the 4 treatment conditions (table e-3, doi.org/ $10.5061 /$ dryad.6n70v4b). Axial disability was the only motor outcome with a significant association with mortality when all motor outcomes were fit simultaneously in a multivariate joint model (table e-4, doi.org/10.5061/dryad.6n70v4b).
The joint model for axial symptoms accurately captures the pattern of survival in our cohort (figure 5A). At an individual level, patients with lower initial severity and faster progression of axial motor symptoms, or higher initial severity and slower progression, both led to a level of axial disability associated with mortality (figure 5B). Modeling 2 causes of mortality (PD and non-PD) as competing risks indicated that axial disability was more strongly associated with risk of death from PD (HR [PD] 3.88 [SE 2.34] vs HR [non-PD] 1.33 [SE $1.87])$, although this difference was not significant $(p=0.44)$.

Finally, we used the joint model for axial symptoms to predict survival for individual patients. We generated these predictions 
Figure 4 The effect of potential unmeasured confounding for each outcome-survival association

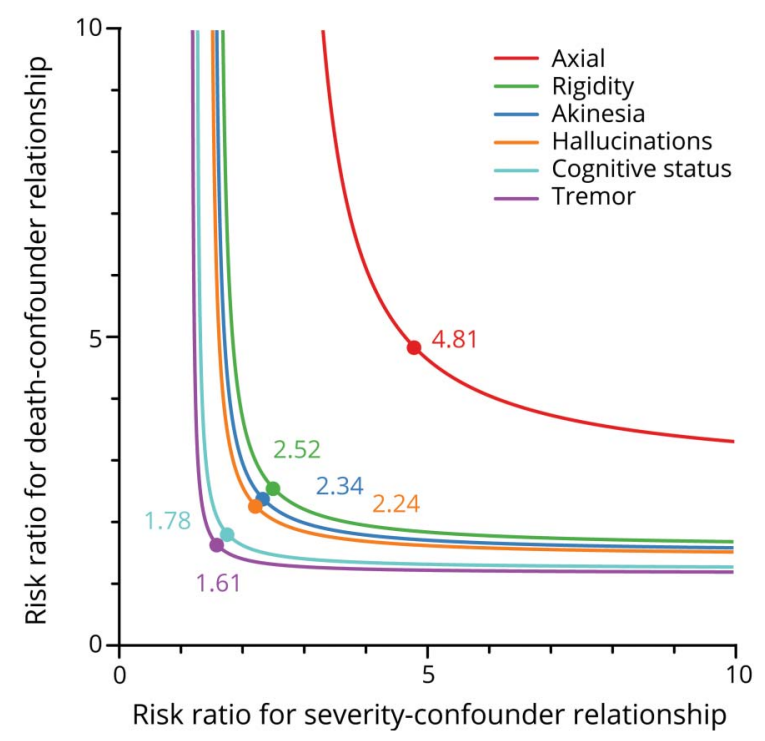

The curves, and all the points to the right of each curve, define joint relationships-combination of severity-confounder and death-confounder associations-that explain away the estimated effect for each outcome. The points represent the E-values, the joint relationship where the confounder associations are equal. The confounder associations are represented on risk ratio scale. Mild unmeasured confounding could explain away the estimated associations between tremor severity and cognitive decline with death. Moderate, yet plausible, unmeasured confounding could explain away the estimated associations between rigidity severity, akinesia severity, and the presence and severity of hallucinations with death. By contrast, quite strong unmeasured confounding is required to explain away the estimated association between current axial symptom severity with death.

by simulating disease progression based on the data up to the last available follow-up (figure 5, C-G). Predictions can be generated after any postsurgical follow-up (figure 6), and could be used by clinicians to dynamically assess risk of death at any point in time as more data become available.

\section{Discussion}

We studied the largest cohort to date of patients with PD followed for such a long duration, with a median longitudinal follow-up lasting 12 years after STN-DBS surgery. We used a joint modeling approach to characterize symptom progression and relate the current level of symptom severity to risk of death. We found that axial motor symptoms became least responsive to treatment by dopaminergic medication, STN-DBS, or their combination, and that axial symptom severity was strongly associated with mortality.

In our patients, all motor symptoms worsened with time in all treatment conditions (with or without medication or STNDBS), except for tremor, which significantly improved. Tremor amelioration or nonaggravation has been described in small cohort studies with 12-20 patients with PD followed for more than 7 years after STN-DBS, ${ }^{2,3,7,20}$ with nearly complete relief on dopaminergic medication. ${ }^{2,3}$ Rigidity is also reported to not significantly worsen with time in 3 of these studies as well as in one additional study of 26 patients with a follow-up period of 11 years. ${ }^{4}$ Lack of aggravation of tremor or rigidity could result from STN-DBS chronically modifying neuronal circuit function, with in particular reduction of abnormal oscillatory activity, ${ }^{21}$ or acting neuroprotectively on remaining dopaminergic neurons. ${ }^{22}$ However, the continuous progression of akinesia and axial motor symptoms in our cohort and in other studies argues against an influence of STN-DBS on disease progression. ${ }^{2,23}$ Indeed, we observed a progressive worsening of both akinesia and axial motor symptoms, and our model predicts that dopaminergic medication and STNDBS become ineffective for ameliorating axial symptoms around 20 years after STN-DBS. This agrees with prior studies of small cohorts of patients with PD more than 10 years after STN-DBS. ${ }^{3,4}$ In 18 patients with PD examined 10 years after STN-DBS, blinded assessment revealed no significant change in akinesia and axial motor signs with STNDBS alone or combined with dopaminergic medication ${ }^{3}$ with an aggravation of $87 \%$ and $102 \%$ of akinesia and axial signs, respectively, when compared to scores before surgery under dopaminergic treatment. In 26 patients with PD examined 11 years after STN-DBS, akinesia worsened by $71 \%$ and axial signs by $38 \%$, respectively, with 17 out of 26 patients who presented falls and 18 out of 26 freezing of gait. ${ }^{4}$ Finally, PD symptoms (akinesia and axial symptoms) progressed similarly in 2 retrospective studies comparing patients with PD with STN-DBS (16 and 12 patients, respectively, in the 2 studies) to patients who declined surgery (14 and 12 patients) during a 6- to 9-year follow-up period. ${ }^{7,20}$

We identified 4 preoperative characteristics associated with higher axial symptom severity after surgery: male sex, higher age at the time of surgery, lower dopa sensitivity, and higher axial symptom severity before surgery, with the last having the largest influence on axial symptom severity after surgery. Higher age at disease onset has previously been shown to be associated with a faster progression rate of axial symptoms and falls in nonoperated patients with PD. ${ }^{24}$ The progression of axial symptoms together with the diminishing efficacy of dopaminergic treatment and STN-DBS implicates dysfunction of additional nondopaminergic systems in the occurrence of refractory axial symptoms including gait and balance disorders. Consistent with this, neural changes have been reported in patients with PD with predominant axial symptoms including falls and freezing of gait, in particular degeneration of neurons within the mesencephalic locomotor region with altered anatomical and functional connectivity with the basal ganglia, the cerebellum, or frontoparietal cortical areas. ${ }^{25-28}$

Forty-one patients (29\%) died during the median follow-up period of 12 years, with an annual mortality rate of $2.2 \%$ and a median total disease duration of 24 years. These results are in line with reports of $30 \%$ and $29 \%$ mortality in 2 cohorts of $79^{5}$ and $41^{3}$ patients with PD, respectively, followed for 10 years after STN-DBS. In comparison, the mortality rate in nonoperated patients with PD is higher, with 

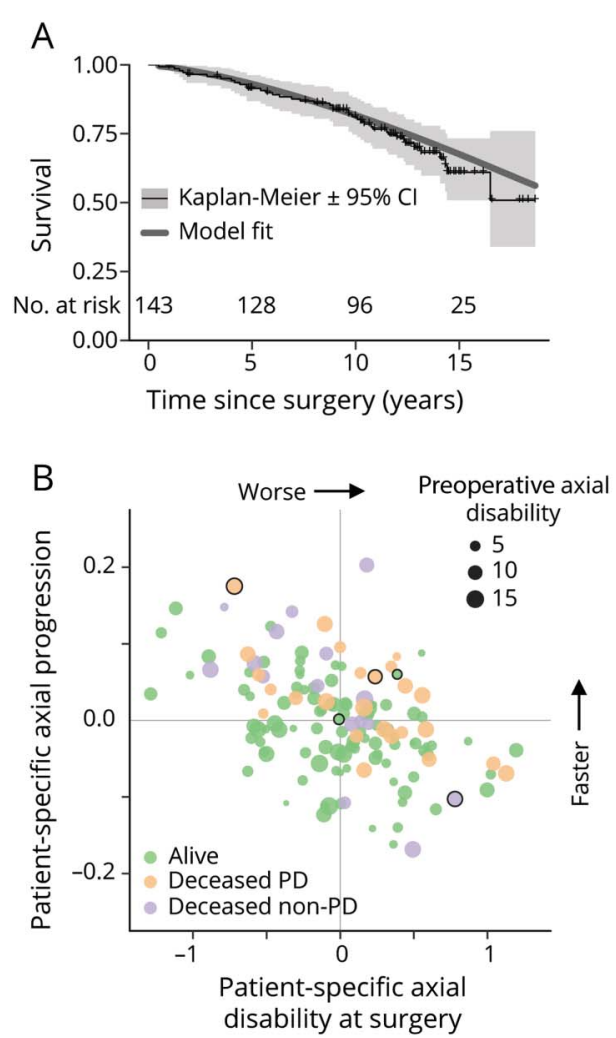
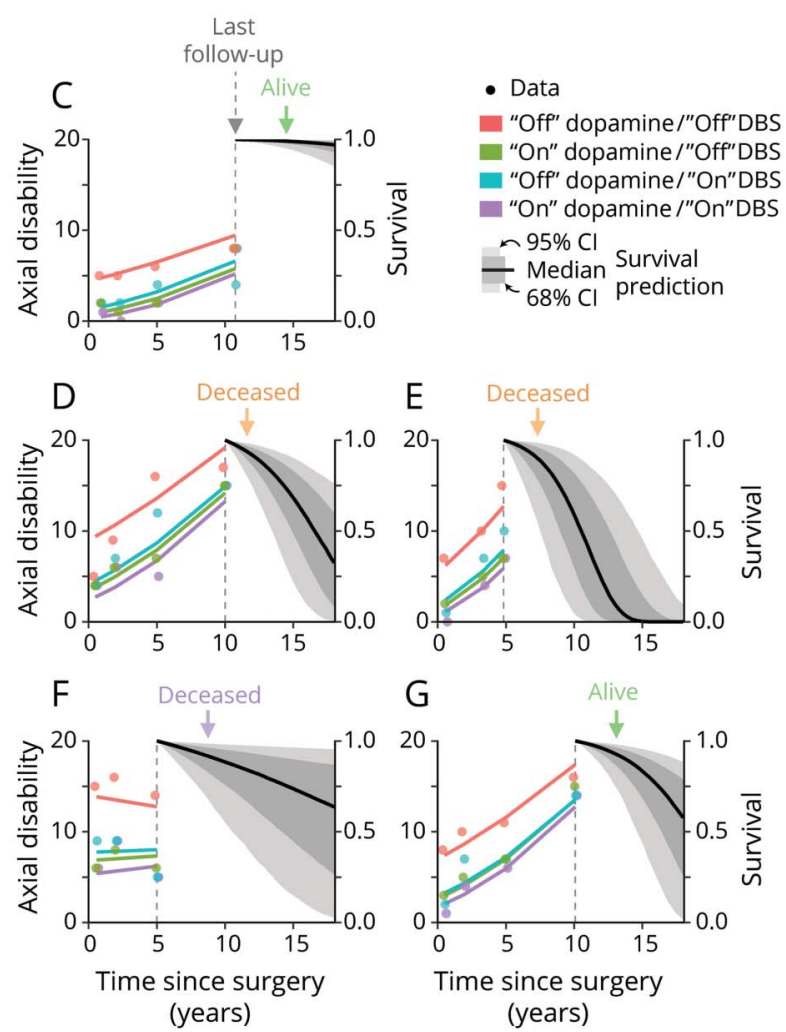

(A) Kaplan-Meier survival estimate with prediction from the survival component of the joint model linking axial symptom severity and mortality. Crosses represent censoring due to death or dropout. (B) Distribution of model random-effects representing predictions for axial severity at surgery and rate of axial progression for each patient. The size of each point is proportional to preoperative axial disability measured without medication ("off" dopamine). (C-G) Dynamic mortality predictions for individual patients (marked with black circles in B). The points correspond to the axial disability measured for each levodopa and stimulation condition. For each patient, mortality prediction was generated via empirical Bayes starting from the time of the last visit (indicated with the dashed vertical line). (C) A patient with axial disability at surgery and rate of axial progression near the population average (centered near 0 in B), and is alive 15 years after surgery. (D, E) Two patients who died from causes related to Parkinson disease. (F) A patient who died suddenly (likely cardiac arrest). (G) A patient with rapid progression of axial symptom severity who was alive at the latest follow-up. $\mathrm{Cl}=\mathrm{confidence}$ interval.

a $54 \%-81 \%$ rate over a follow-up period of $12-20$ years. $^{29-31}$ Three retrospective studies report that the mortality rate is higher in nonoperated $(41,23$ and 611 patients, respectively) compared to operated patients with PD (106, 24, and 611 patients, respectively), with a follow-up period of 1-8 years. ${ }^{7,8,32}$ These data suggest that STN-DBS patients with PD survive longer. Strict selection of patients with PD for STN-DBS with younger age, absence of cognitive deficit, and a levodopa-responsive form of the disease ${ }^{10}$ represent demographic and clinical factors that could contribute to this favorable outcome with STN-DBS. Indeed, 73 out of our 143 patients with PD (51\%) had a young-onset (YO) form of PD with an onset before age 45. Indeed, patients with YO PD have a better response to the dopaminergic treatment and STN-DBS ${ }^{33}$ and are at lower risk for developing dementia. ${ }^{34}$ This, along with higher preoperative cognitive status, could explain the low rate of dementia observed in our cohort, with only 39 out of 90 patients (43\%) diagnosed with dementia at the last follow-up visit relative to the rate of $80 \%$ reported in nonoperated patients with PD after 20 years of disease progression. ${ }^{35}$ STN-DBS may also prolong survival through a long-lasting benefit on parkinsonian disability with decreased swallowing disorders and aspiration pneumonia, ${ }^{8}$ and reduced dopaminergic medication with subsequently less related motor and cognitive complications. ${ }^{7}$ Finally, STN-DBS patients with PD could have benefitted from better care due to surgery and device implantation that required more intense follow-up in an expert PD center.

The main cause of death in our cohort was disease progression $(\mathrm{n}=25)$ with aspiration pneumonia in 7 patients. This is consistent with other mortality reports in patients with PD with $\mathrm{DBS},{ }^{7,8,32}$ but also in nonoperated patients with PD. ${ }^{31}$ Our joint models indicated that the level of axial symptom severity in the follow-up period was the main significant risk factor for death. This is consistent with the identification of postural instability gait disorders phenotype ${ }^{31}$ and recurrent falls as independent risk factors for death in nonoperated patients with PD. ${ }^{36}$ We note, however, that the majority of our patients did not die directly from falling. This suggests that while axial symptoms may increase the risk of falling, these symptoms may be directly or indirectly related to death in other ways. For example, institutionalization ${ }^{24}$ and being 

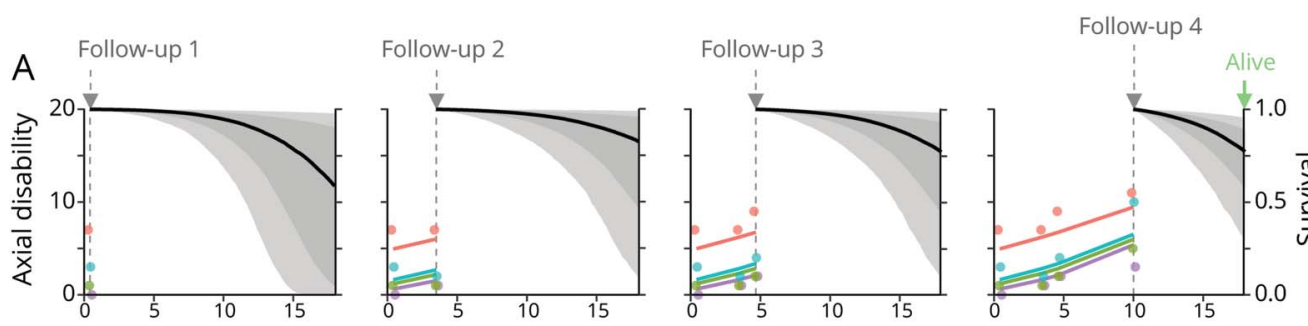

- Data

- "Off" dopamine/"Off"DBS

"On" dopamine/"Off"DBS

- "Off" dopamine/"On"DBS
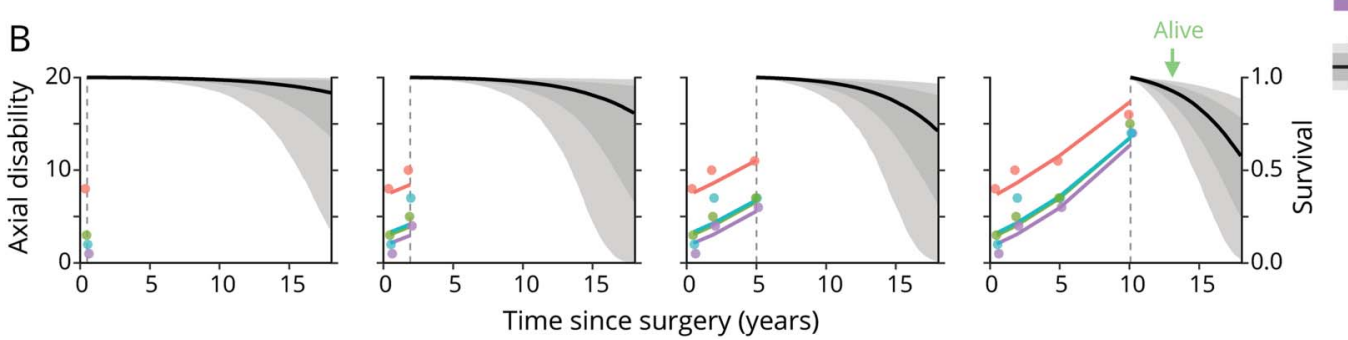

"On" dopamine/"On" DBS

$\sim 95 \% \mathrm{Cl}$

- Median Survival

$68 \% \mathrm{Cl}$ prediction

The separate panels in each row represent mortality predictions using all postsurgical axial severity scores up to a particular examination for 2 patients. The points correspond to the axial disability measured for each dopaminergic medication and (STN-DBS) condition. Mortality predictions were generated via empirical Bayes starting from the time of the last visit (indicated with the dashed vertical line). Each column illustrates the mortality prediction assuming that data were available to a particular examination. (A) A patient with slow progression of axial symptom severity. (B) A patient with faster progression of axial symptom severity. $\mathrm{Cl}=$ confidence interval; DBS = deep brain stimulation.

chronically bedridden may lead to specific medical complications, such as pulmonary embolism or infection.

While our results are consistent with the unique status of axial symptom severity in predicting mortality, the HRs for associations between akinesia and rigidity and mortality are greater than 1. We do not believe that this necessarily indicates that the severity of akinesia and rigidity symptoms is substantively associated with mortality, even if more data are added. Indeed, preoperative axial symptom severity was the only symptom associated with increased mortality for every outcome model except axial symptoms (figure 3; figure e-2, doi.org/10.5061/ dryad.6n70v4b). By contrast, preoperative axial symptom severity is not significant in the model incorporating axial symptom progression, and controlling for preoperative axial symptom severity decreased both the magnitude and significance of mortality associations with akinesia and rigidity. These results indicate that current level of axial symptom severity is relevant for predicting mortality. Moreover, the associations between akinesia and rigidity symptom severity and mortality are substantially smaller than between axial symptom severity and mortality, with an HR (4.3) that is unlikely to be explained away by unmeasured confounders (figure 4). Finally, fitting a multivariate joint model that simultaneously models the progression of akinesia, rigidity, tremor, and axial symptoms revealed that only the current level of axial symptom severity was significantly associated with mortality (table e-4, doi.org/10.5061/dryad.6n70v4b).

There are several limitations to consider in interpretating the results of our study. The cause of death was not clearly identified, since no autopsy was performed, in 15 of the 25 patients who died of PD progression. However, in other large cohort studies, PD progression is also reported as the main cause of death without indication of a more precise cause of death. ${ }^{37}$ More specific information on cause of death may provide clearer insight into the mechanisms linking axial symptom severity and death. The fact that STN-DBS and dopamine treatments were assessed in the same order at each visit may have influenced the effect of each treatment condition on motor outcome measures. We measured PD motor disability progression using the UPDRS-III, which is a semiquantitative scale. This scale has been rigorously validated in large trials to assess the effects of STN-DBS, ${ }^{38}$ and changes in this scale have been shown to reflect the patient's perception of change in disease status. ${ }^{12}$ Although the subscores were well-fit by the longitudinal submodel of our joint models, the subscores were constructed from a relatively limited number of items. While our results indicate that axial symptoms are the most relevant predictor of death, clinical scales more focused on gait and balance disorders, such as the Gait and Balance Scale, ${ }^{39}$ or data from wearable devices may provide clearer insight into the link between axial symptoms and cause of death. Finally, while we internally validated our data using bootstrapped prediction scores, external validation using data from other cohorts will be important for confirming our results. Examining larger samples over longer periods will also be important for confirming the predictive status of current axial symptom severity in patients with slowly progressing axial symptoms, and may reveal that other motor symptoms become significant and predictive at later stages of PD.

We showed that it is possible to predict the risk of death in individual STN-DBS patients with PD using the current level of axial symptom severity. Our data have important implications 
for clinicians, providing a metric by which they could adapt treatments and rehabilitation programs to anticipate PD progression and care of these patients with a good understanding of the long-term effects of STN-DBS. Our study also gives useful information for designing and elaborating interventional trials aimed at modifying the course of the disease or mortality, in particular, trials aiming to improve axial symptoms and falls with drug treatment, ${ }^{40}$ optimization of stimulation parameters, ${ }^{41}$ or physical training. ${ }^{42,43}$ Finally, our data may provide clinical insight for new imaging approaches used to measure disease progression, such as nigrosome and neuromelanin imaging ${ }^{44}$ or for basal ganglia neuronal activity recordings. ${ }^{45}$

\section{Acknowledgment}

The authors thank the patients who participated in this study and Drs. Vincent Guillemot and Arthur Tenenhaus (Biostatistics Core Facility ICM) and Drs. Xavier Jouven and Jean-Philippe Empana (Paris Cardiovascular Research Center) for discussion.

\section{Study funding}

This study was supported by the Institut National de la Recherche Médicale (INSERM) and the 'Investissements d'avenir' program (ANR-10-IAIHU-06 and ANR-11-INBS0006). B.L. and C.K. were supported by grants from the ATIPAvenir program and Sanofi-Aventis R\&D. N.M. was supported by a grant from the Swiss National Science Foundation.

\section{Disclosure}

B. Lau, N. Meier, G. Serra, V. Czernecki, M. Schuepbach, S. Navarro, and P. Cornu report to disclosures relevant to the manuscript. D. Grabli reports personal fees and nonfinancial support from AbbVie, nonfinancial support from Zambon, grants from DGOS, and nonfinancial support from MERZ, outside the submitted work. Y. Agid, M. Vidailhet, and C. Karachi report no disclosures relevant to the manuscript. M.-L. Welter reports personal fees from Medtronic and a grant from Michael J. Fox Foundation for Parkinson's disease, outside the submitted work. Go to Neurology.org/N for full disclosures.

\section{Publication history}

Received by Neurology August 3, 2018. Accepted in final form January $25,2019$.

\section{Appendix Authors}

\begin{tabular}{|c|c|c|c|}
\hline Name & Location & Role & Contribution \\
\hline B. Lau & $\begin{array}{l}\text { Brain and Spine } \\
\text { Institute, GHPS } \\
\text { Paris, France }\end{array}$ & $\begin{array}{l}\text { Data } \\
\text { management, } \\
\text { statistical analysis }\end{array}$ & $\begin{array}{l}\text { Project design, } \\
\text { analyzed the } \\
\text { data, writing } \\
\text { original draft, } \\
\text { review and } \\
\text { editing, } \\
\text { supervision }\end{array}$ \\
\hline N. Meier & $\begin{array}{l}\text { Neurology } \\
\text { Department, } \\
\text { Bern Hospital, } \\
\text { Switzerland }\end{array}$ & $\begin{array}{l}\text { Site investigator } \\
\text { neurologist }\end{array}$ & $\begin{array}{l}\text { Investigation, } \\
\text { revised the } \\
\text { manuscript for } \\
\text { intellectual } \\
\text { content }\end{array}$ \\
\hline
\end{tabular}

Appendix (continued)

\begin{tabular}{|c|c|c|c|}
\hline Name & Location & Role & Contribution \\
\hline G. Serra & $\begin{array}{l}\text { Clinical } \\
\text { Investigation } \\
\text { Center, GHPS, } \\
\text { Paris, France }\end{array}$ & $\begin{array}{l}\text { Site investigator } \\
\text { neurologist }\end{array}$ & $\begin{array}{l}\text { Investigation, } \\
\text { revised the } \\
\text { manuscript for } \\
\text { intellectual } \\
\text { content }\end{array}$ \\
\hline V. Czernecki & $\begin{array}{l}\text { Neurology } \\
\text { Department, } \\
\text { GHPS, APHP, } \\
\text { Paris, France }\end{array}$ & $\begin{array}{l}\text { Site investigator, } \\
\text { neuropsychologist }\end{array}$ & $\begin{array}{l}\text { Investigation, } \\
\text { revised the } \\
\text { manuscript for } \\
\text { intellectual } \\
\text { content }\end{array}$ \\
\hline $\begin{array}{l}\text { M. } \\
\text { Schuepbach }\end{array}$ & $\begin{array}{l}\text { Neurology } \\
\text { Department, } \\
\text { Bern Hospital, } \\
\text { Switzerland }\end{array}$ & $\begin{array}{l}\text { Site investigator, } \\
\text { neurologist }\end{array}$ & $\begin{array}{l}\text { Investigation, } \\
\text { revised the } \\
\text { manuscript for } \\
\text { intellectual } \\
\text { content }\end{array}$ \\
\hline S. Navarro & $\begin{array}{l}\text { Neurosurgery } \\
\text { Department, } \\
\text { GHPS, Paris, } \\
\text { France }\end{array}$ & $\begin{array}{l}\text { Site investigator, } \\
\text { neurologist }\end{array}$ & $\begin{array}{l}\text { Investigation, } \\
\text { revised the } \\
\text { manuscript for } \\
\text { intellectual } \\
\text { content }\end{array}$ \\
\hline P. Cornu & $\begin{array}{l}\text { Neurosurgery } \\
\text { Department, } \\
\text { GHPS, Paris, } \\
\text { France }\end{array}$ & $\begin{array}{l}\text { Site investigator, } \\
\text { neurologist }\end{array}$ & $\begin{array}{l}\text { Investigation, } \\
\text { revised the } \\
\text { manuscript } \\
\text { for } \\
\text { intellectual } \\
\text { content }\end{array}$ \\
\hline
\end{tabular}

\begin{tabular}{llll}
\hline D. Grabli & $\begin{array}{l}\text { Neurology } \\
\text { Department, } \\
\text { GHPS, Paris, } \\
\text { France }\end{array}$ & $\begin{array}{l}\text { Site investigator, } \\
\text { neurologist }\end{array}$ & $\begin{array}{l}\text { Investigation, } \\
\text { revised the } \\
\text { manuscript for } \\
\text { intellectual } \\
\text { content }\end{array}$ \\
\hline Y. Agid & $\begin{array}{l}\text { Brain and Spine } \\
\text { Institute, GHPS } \\
\text { Paris, France }\end{array}$ & $\begin{array}{l}\text { Site investigator, } \\
\text { neurologist }\end{array}$ & $\begin{array}{l}\text { Investigation, } \\
\text { revised the } \\
\text { manuscript for } \\
\text { intellectual } \\
\text { content }\end{array}$ \\
\hline
\end{tabular}

\begin{tabular}{llll}
\hline M. Vidailhet & $\begin{array}{l}\text { Neurology } \\
\text { Department, } \\
\text { GHPS, Paris, }\end{array}$ & $\begin{array}{l}\text { Site investigator, } \\
\text { neurologist }\end{array}$ & $\begin{array}{l}\text { Investigation, } \\
\text { revised the } \\
\text { France }\end{array}$ \\
& & $\begin{array}{l}\text { manuscript for } \\
\text { intellectual } \\
\text { content }\end{array}$ \\
\hline
\end{tabular}

\begin{tabular}{|c|c|c|c|}
\hline C. Karachi & $\begin{array}{l}\text { Neurosurgery } \\
\text { Department, } \\
\text { GHPS, APHP, } \\
\text { Paris, France }\end{array}$ & $\begin{array}{l}\text { Site investigator, } \\
\text { neurosurgeon }\end{array}$ & $\begin{array}{l}\text { Project design, } \\
\text { investigation, } \\
\text { writing } \\
\text { original draft, } \\
\text { review and } \\
\text { editing, } \\
\text { supervision }\end{array}$ \\
\hline M.L. Welter & $\begin{array}{l}\text { Neurophysiology } \\
\text { Department, } \\
\text { CHU Rouen, } \\
\text { France }\end{array}$ & $\begin{array}{l}\text { Principal } \\
\text { investigator, } \\
\text { neurologist }\end{array}$ & $\begin{array}{l}\text { Project design, } \\
\text { investigation, } \\
\text { writing } \\
\text { original draft, } \\
\text { review and } \\
\text { editing, } \\
\text { supervision, } \\
\text { fundraising }\end{array}$ \\
\hline
\end{tabular}

\section{References}

1. Krack P, Batir A, Van Blercom N, et al. Five-year follow-up of bilateral stimulation of the subthalamic nucleus in advanced Parkinson's disease. N Engl J Med 2003;349:1925-1934.

2. Fasano A, Romito LM, Daniele A, et al. Motor and cognitive outcome in patients with Parkinson's disease 8 years after subthalamic implants. Brain 2010;133:2664-2676.

3. Castrioto A, Lozano AM, Poon YY, Lang AE, Fallis M, Moro E. Ten-year outcome of subthalamic stimulation in Parkinson disease: a blinded evaluation. Arch Neurol 2011;68:1550-1556. 
4. Rizzone MG, Fasano A, Daniele A, et al. Long-term outcome of subthalamic nucleus DBS in Parkinson's disease: from the advanced phase towards the late stage of the disease? Parkinsonism Relat Disord 2014;20:376-381.

5. Bang Henriksen M, Johnsen EL, Sunde N, Vase A, Gjelstrup MC, Østergaard K. Surviving 10 years with deep brain stimulation for Parkinson's disease: a follow-up of 79 patients. Eur J Neurol 2016;23:53-61.

6. Macleod AD, Taylor KS, Counsell CE. Mortality in Parkinson's disease: a systematic review and meta-analysis. Mov Disord 2014;29:1615-1622.

7. Merola A, Rizzi L, Zibetti M, et al. Medical therapy and subthalamic deep brain stimulation in advanced Parkinson's disease: a different long-term outcome? J Neurol Neurosurg Psychiatry 2013;85:552-559.

8. Ngoga D, Mitchell R, Kausar J, Hodson J, Harries A, Pall H. Deep brain stimulation improves survival in severe Parkinson's disease. J Neurol Neurosurg Psychiatry 2014;85:17-22.

9. Rocha S, Monteiro A, Linhares P, et al. Long-term mortality analysis in Parkinson's disease treated with deep brain stimulation. Parkinsons Dis 2014;2014:717041.

10. Welter ML, Schüpbach M, Czernecki V, et al. Optimal target localization for subthalamic stimulation in patients with Parkinson disease. Neurology 2014;82:1352-1361.

11. Defer GL, Widner H, Marié RM, Rémy P, Levivier M. Core assessment program for surgical interventional therapies in Parkinson's disease (CAPSIT-PD). Mov Disord 1999; 14:572-584.

12. Martinez-Martin P, Gil-Nagel A, Gracia LM, Gomez JB, Martinez-Sarries J, Bermejo F. Unified Parkinson's Disease Rating Scale characteristics and structure: The Cooperative Multicentric Group. Mov Disord 1994;9:76-83.

13. Mattis S, ed. Dementia Rating Scale. Odessa, FL: Psychological Assessment Resources; 1988.

14. Rizopoulos D. Joint Models for Longitudinal and Time-To-Event Data with Applications. Boca Raton, FL: Chapman\&Hall/CRC Texts in Statistical Science Series; 2012.

15. VanderWeele TJ, Ding P. Sensitivity analysis in observational research: introducing the E-value. Ann Intern Med 2017;167:268-274.

16. VanderWeele TJ. Unmeasured confounding and hazard scales: sensitivity analysis for total, direct, and indirect effects. Eur J Epidemiol 2013;28:113-117.

17. Patel CJ, Burford B, Ioannidis JP. Assessment of vibration of effects due to model specification can demonstrate the instability of observational associations. J Clin Epidemiol 2015;68:1046-1058.

18. Harrell FE Jr, Lee KL, Mark DB. Multivariable prognostic models: issues in developing models, evaluating assumptions and adequacy, and measuring and reducing errors. Stat Med 1996;15:361-387.

19. Colin Cameron A, Miller DS. A practitioner's guide to cluster-robust inference. J Hum Resour 2015;50:317-372.

20. Lilleeng B, Brønnick K, Toft M, Dietrichs E, Larsen JP. Progression and survival in Parkinson's disease with subthalamic nucleus stimulation. Acta Neurol Scand 2014; 130:292-298.

21. Beudel M, Little S, Pogosyan A, et al. Tremor reduction by deep brain stimulation is associated with gamma power suppression in Parkinson's disease. Neuromodulation 2015;18:349-354.

22. Wallace BA, Ashkan K, Heise CE, et al. Survival of midbrain dopaminergic cells after lesion or deep brain stimulation of the subthalamic nucleus in MPTP-treated monkeys. Brain 2007;130:2129-2145.

23. Shaw VE, Keay KA, Ashkan K, Benabid AL, Mitrofanis J. Dopaminergic cells in the periaqueductal grey matter of MPTP-treated monkeys and mice; patterns of survival and effect of deep brain stimulation and lesion of the subthalamic nucleus. Parkinsonism Relat Disord 2010;16:338-344.

24. Kempster PA, Williams DR, Selikhova M, Holton J, Revesz T, Lees AJ. Patterns of levodopa response in Parkinson's disease: a clinico-pathological study. Brain 2007; 130:2123-2128.
25. Karachi C, Grabli D, Bernard FA, et al. Cholinergic mesencephalic neurons are involved in gait and postural disorders in Parkinson disease. J Clin Invest 2010;120: 2745-2754.

26. Shine JM, Matar E, Ward PB, et al. Exploring the cortical and subcortical functional magnetic resonance imaging changes associated with freezing in Parkinson's disease. Brain 2013;136:1204-1215.

27. Müller ML, Albin RL, Kotagal V, et al. Thalamic cholinergic innervation and postural sensory integration function in Parkinson's disease. Brain 2013;136:3282-3289.

28. Bohnen NI, Frey KA, Studenski SA, et al. Gait speed in Parkinson disease correlates with cholinergic degeneration. Neurology 2013;81:1611-1616.

29. Forsaa EB, Larsen JP, Wentzel-Larsen T, Alves G. What predicts mortality in Parkinson disease?: a prospective population-based long-term study. Neurology 2010;75 1270-1276.

30. Posada IJ, Benito-León J, Louis ED, et al. Mortality from Parkinson's disease: a population-based prospective study (NEDICES). Mov Disord 2011;26:2522-2529.

31. Bäckström D, Granåsen $\mathrm{G}$, Domellöf $\mathrm{ME}$, et al. Early predictors of mortality in parkinsonism and Parkinson disease: a population-based study. Neurology 2018;91: e2045-e2056.

32. Weaver FM, Stroupe KT, Smith B, et al. Survival in patients with Parkinson's disease after deep brain stimulation or medical management. Mov Disord 2017;32: $1756-1763$.

33. Merola A, Zibetti M, Artusi CA, et al. Subthalamic nucleus deep brain stimulation outcome in young onset Parkinson's disease: a role for age at disease onset? J Neurol Neurosurg Psychiatry 2012;83:251-257.

34. Schrag A, Hovris A, Morley D, Quinn N, Jahanshahi M. Young- versus older-onset Parkinson's disease: impact of disease and psychosocial consequences. Mov Disord 2003; 18:1250-1256

35. Hely MA, Reid WG, Adena MA, Halliday GM, Morris JG. The Sydney multicenter study of Parkinson's disease: the inevitability of dementia at 20 years. Mov Disord 2008;23:837-844.

36. Kempster PA, O'Sullivan SS, Holton JL, Revesz T, Lees AJ. Relationships between age and late progression of Parkinson's disease: a clinico-pathological study. Brain 2010 133:1755-1762.

37. Tuck KK, Zive DM, Schmidt TA, Carter J, Nutt J, Fromme EK. Life-sustaining treatment orders, location of death and co-morbid conditions in decedents with Parkinson's disease. Parkinsonism Relat Disord 2015;21:1205-1209.

38. Schuepbach WM, Rau J, Knudsen K, et al. Neurostimulation for Parkinson's disease with early motor complications. N Engl J Med 2013;368:610-622.

39. Thomas M, Jankovic J, Suteerawattananon M, et al. Clinical gait and balance scale (GABS): validation and utilization. J Neurol Sci 2004;217:89-99.

40. Henderson EJ, Lord SR, Brodie MA, et al. Rivastigmine for gait stability in patients with Parkinson's disease (ReSPonD): a randomised, double-blind, placebocontrolled, phase 2 trial. Lancet Neurol 2016;15:249-258.

41. Fasano A, Aquino CC, Krauss JK, Honey CR, Bloem BR. Axial disability and deep brain stimulation in patients with Parkinson disease. Nat Rev Neurol 2015;11:98-110.

42. Mirelman A, Rochester L, Maidan I, et al. Addition of a non-immersive virtual reality component to treadmill training to reduce fall risk in older adults (V-TIME): a randomised controlled trial. Lancet 2016;388:1170-1182.

43. Mak MK, Wong-Yu IS, Shen X, Chung CL. Long-term effects of exercise and physical therapy in people with Parkinson disease. Nat Rev Neurol 2017;13:689-703.

44. Pavese N, Tai YF. Nigrosome imaging and neuromelanin sensitive MRI in Diagnostic evaluation of parkinsonism. Mov Disord Clin Pract 2018;5:131-140.

45. Quinn EJ, Blumenfeld Z, Velisar A, et al. Beta oscillations in freely moving Parkinson's subjects are attenuated during deep brain stimulation. Mov Disord 2015;30: $1750-1758$. 


\section{Neurology}

\section{Axial symptoms predict mortality in patients with Parkinson disease and subthalamic stimulation}

Brian Lau, Niklaus Meier, Giulia Serra, et al.

Neurology 2019;92;e2559-e2570 Published Online before print May 1, 2019

DOI 10.1212/WNL.0000000000007562

\section{This information is current as of May 1, 2019}

\section{Updated Information \& Services}

References

Citations

Subspecialty Collections

Permissions \& Licensing

Reprints including high resolution figures, can be found at: http://n.neurology.org/content/92/22/e2559.full

This article cites 43 articles, 6 of which you can access for free at: http://n.neurology.org/content/92/22/e2559.full\#ref-list-1

This article has been cited by 1 HighWire-hosted articles: http://n.neurology.org/content/92/22/e2559.full\#\#otherarticles

This article, along with others on similar topics, appears in the following collection(s):

Clinical trials Observational study (Cohort, Case control)

http://n.neurology.org/cgi/collection/clinical_trials_observational_stud y_cohort_case_control

Cohort studies

http://n.neurology.org/cgi/collection/cohort_studies

Parkinson's disease/Parkinsonism

http://n.neurology.org/cgi/collection/parkinsons_disease_parkinsonism

Information about reproducing this article in parts (figures,tables) or in its entirety can be found online at:

http://www.neurology.org/about/about_the_journal\#permissions

Information about ordering reprints can be found online:

http://n.neurology.org/subscribers/advertise

Neurology ${ }^{\circledR}$ is the official journal of the American Academy of Neurology. Published continuously since 1951, it is now a weekly with 48 issues per year. Copyright Copyright @ 2019 The Author(s). Published by Wolters Kluwer Health, Inc. on behalf of the American Academy of Neurology.. All rights reserved. Print ISSN: 0028-3878. Online ISSN: 1526-632X.

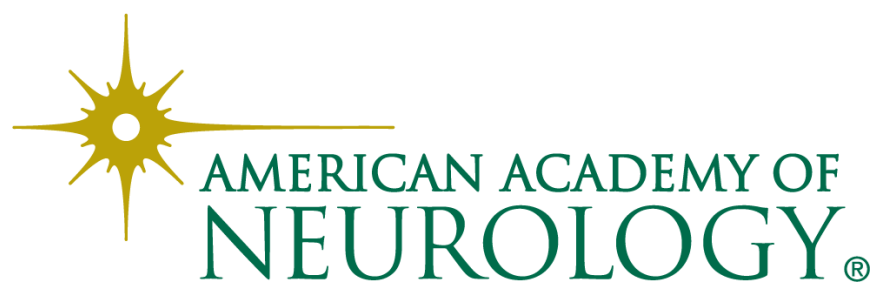

